\title{
Figuring out Zhangyong's Leadership Style by His Way of Handling the Crisis in Haidilao Jinsong and Sun Palace Stores
}

\author{
Jing $\mathrm{Wu}^{1, \mathrm{a}}$ \\ ${ }^{1}$ Business School of Jianghan University, Wuhan, Hubei, China \\ ajeannewu@163.com
}

keywords: Haidilao, transformational leadership, vision, self development

\begin{abstract}
From Haidilao management's handling the kitchen's hygiene events in Beijing Jinsong and Sun Palace stores, this article discussed Zhang Yong's transformational leadership style, and how his transformational leadership style positively influenced Haidilao's employees, environment and culture. At the same time, it pointed out that with the expanding of Haidilao, it would be more important to cope with its big enterprises diseases, otherwise the crisis will come back again at any time.
\end{abstract}

\section{Introduction}

In August25 2017, The reporter released a video recording the employees' illegal operation of violating food safety and hygiene standards in the kitchens of Haidilao Hot Pot in Jinsong and Beijing Sun Palace.

In a few hours, the Haidilao management posted an announcement about this issue. They acknowledged the fact that there were food hygiene safety risks in the two stores, and announced that they would take steps to solve the problem. The main measures were summarized as follows: First, not only for these two stores, but for all stores to conduct a comprehensive inspection, to build a "bright kitchen", informatization and visualization; Second, to ensure that all stores in the future comply with local laws and regulations, and welcome customers, media, management departments to inspect and supervise the stores; Third, employees and related managers involved in the incident didn't need to be panic, just in accordance with the requirements of the system for rectification and assume corresponding responsibilities. The problems are from the management, the board takes the main responsibility.[1]

Did not like other carting enterprises' response to the crisis in the same situation, Haidilao responded the public in the first time, admitted mistakes and gave specific corrective methods. What particularly worth mentioning is that they did not announce the expulsion of personnel involved, but admitted that the main responsibility in the management, reflecting their humanistic care. Surprisingly, many customers were not responding to spit but to forgive.

But why? Why customers choose to forgive Haidilao even after watching such a disgusting video?This is just what this paper will talk about.

For more than ten years, Haidilao has always been famous for its unique service in the catering industry. It has such high customer loyalty that people are even willing to wait two hours for a meal. Open the Haidilao official website, it is not difficult to find that the company values innovation and encourages personalized service. The management delivers the philosophy of "hands change fate", and creates equitable environment for each employee. This time, their approach to the crisis coincided with the values they had consistently pursued, which is "implements human-based management and affection management, to promote employees".

In Zhangyong's words, "Creativity is not the implementation, but the natural result of employee satisfaction, and employee satisfaction is the only way to satisfy customers."

It is just Zhang Yong's "love employees as family" management concept, stimulated the creativity of employees. They came up with various ways to meet customer demand, thereby ensuring a high degree of customer loyalty. That's why, after the crisis, customers still chose to forgive them. High customer loyalty is an important symbol of the success of service enterprises. 
How did Zhang Yong make it happen? This paper tries to explain it by analyzing Zhang Yong's leadership style.

\section{Definition of the main concept}

Transformational leadership is a style of leadership where a leader works with subordinates to identify needed change, creating a vision to guide the change through inspiration, and executing the change together with loyal members of the team.

\section{Main discussion}

Zhang Yong is just this type. But what made him become a leader of transformational style?

\subsection{People first, then a vision.}

In the company's early days, Zhang Yong worked together with his employees, set an example for them. Inspired by him, the employees totally devoted themselves into their Haidilao, improved the formula and made the hot pot more and more delicious. Zhang Yong respected his employees, trusted them, supported them and cultivated them, made them become what they wanted to be, they created "hands change fate" philosophy together and made it their vision, their mutual vision. Then they passed the philosophy to every new comer and encouraged them to work hard to get better life. Gradually, the employees found that Haidilao was just like a big family, and as a member of it, every one should devote his efforts to make it better. "Respect, trust and care for each person" then became the core values of Haidilao. [2]

Unless a vision is sustained by action,it quickly turns to ashes[3](Neol Tichy). On the contrary, practicing core values and working hard to achieve the vision make Haidilao a successful company.

\subsection{Create an environment to improve employee performance.}

Creating goals can help clarify long-term vision and motivate staff to get there. Again, with employees' participating, they figured out their specific mutually agreed upon goals and progressively transmitted to all levels and different departments of the company. But on how to evaluate the performance, Zhang Yong had his own consideration. He found that other companies were using sales and profit margins as the main indicators, but this was not conducive to motivating front-line employees. Due to the decisive factor for a catering business is customer acceptance, customer satisfaction assessment was clearly the most important indicators, and only by improving employee satisfaction can customer satisfaction be improved, Zhang Yong decided that in Haidilao, only evaluate employee satisfaction and customer satisfaction. That means, for first-line staff, only measure customer satisfaction; for managers, measure customer satisfaction and employee satisfaction. In order to improve customer satisfaction, each employee was given big or small authority. Values and institutions can shape human behaviors. Empowered employees showed great creativity, and a variety of small ideas emerged in an endless stream.Customers often felt that they had received "value added" service, and their loyalty had been continuously improved. In front of his employees, Zhang Yong always showed that he care. He trusted people, gave them responsibility and pushed them, he conducted to bring out the best in them, helped them grow up to what they wanted to be. "Treat a man as he is and he will remain as he is. Treat a man as he can and should be and he shall become as he can and should be.’[4]( Johan Wolfgang Van Goethe)

\subsection{A fair performance evaluation and reward system promotes employee growth and organizational commitment.}

Empowerment improved job satisfaction, task performance, and organizational citizenship behavior of employees. But it is a tough job. You have to do a lot of preparation before making a reasonable empowerment. Training is the most important thing. Help them get relavant knowledge, skills and capable to accomplish various tasks well, and let them know your expectations. With an eye to give employees more and more responsibility over time. By delegating more and more trust and by teaching them and thereby expanding their capabilities, Zhang Yong trained a fighting team. His 
team members (like Yuanhuaqiang )then transmited their vision and values and skills to their subordinates, furthermore, to direct their behaviors. Like Zhan Yong said, "Performance management is the hoe, knowledgeable managers will be able to remove weeds and keep the seedlings.'[5] Zhang Yong did his best to train his subordinates to distinguish weeds and seedlings. In Haidilao, Performance management was not to check the key performance indicators, but to check the customer satisfaction, employee satisfaction by observing their behaviors, and then gave appropriate rewards or punishments. Because a lot of evaluation of service industry was unable to quantify, it was particularly important to assure the managers' having those competence to evaluate their subordinates' performance. This required the supervisor to understand the core values of the company, and had the ability to assess if the employee's behavior met requirements from the perspective of the company's value, and whether the supervisor had the ability to distinguish weeds and seedlings.

Zhang Yong was obviously doing well. The performance appraisal system of Haidilao made the talents outstanding, and improved the staff's organizational commitment, and employees showed more organizational citizenship behaviors.

\section{Conclusions and Suggestions}

In a word, to develop employees' skills and help them to grow up to become what they wanted to be is the best way to improve their performance, enhance their organizational commitment, and reduce turnover. Especially for people who were in ego-identity confusion or moratorium status, with the increasement of perceived organizational support, their job involvement improved significantly[6]. This also explains why Zhang Yong was always willing to recruit migrant workers without a degree, because their ego-identity have not yet reached the commitment status. They came to Haidilao, grew up under the consideration of the organization, gradually accepted Haidilao's values and vision, figured out their occupation target, and consciously accepted the rules and regulations of the organization. Like members of a family answered the parent's call, the "family rules" guided and shaped their behaviors and they involved themselves in hard working to honor their family . With Haidilao access to customers and the public recognition, they found more meanings form their jobs, which would further stimulate their job involvements, explored more their ego-identities, resulted in a more fully self development, along with the growth of the organization.

Respect employees, trust employees, empower employees and support employees, that is Zhang Yong's secrets of managing Haidilao, it is also his leadership style led Haidilao to where it is now.This is also the main reason why management chose to assume primary responsibility rather than directly dismiss related employees when the crisis in Jinsong and Sun palace happened. This is exactly the reflection of the culture of Haidilao.

But the point is that Haidilao is no longer a small hot pot store anymore. As a large catering enterprise with a staff of 15000 people and sales revenue of 3 billion yuan, whether family culture can still meet the requirement of the future development, this is a question worth considering. After all, the front-line staff has become more and more distant from Zhang Yong, and every time employees make mistakes, are the board of directors always responsible for it?

Research evidence suggests that when it is properly implemented, punishment leads to positive organizational outcomes. When punishment is implemented on a contingency basis, it will help to improve job satisfaction, reduce role ambiguity and absenteeism. Depend on the specific behavior being punished, may have a positive impact on performance[7]. On Haidilao's home page, you can easily find the results of each time's hygiene inspection, but you can't see the corresponding rewards and penalties. It is time for Haidilao to improve the work process and the reward\& punishment system itself, which requires the management's wisdom and a well-trained, high-quality and responsible cadre and staff working together. Otherwise, the next crisis will come again soon.

\section{Acknowledgement}

This paper is supported by the construction of "economic and industrial integration management of 
Urban Agglomeration", which is the dominant characteristic discipline group of Hubei provincial universities.

\section{References:}

[1] http://finance.ifeng.com/a/20170825/15606941_0.shtml

[2] http://www.haidilao.com/sg/index.php?m=content\&c=index\&a=lists\&catid=2

[3] The Transformational Leader - with Mary Anne Devanna, (1990) Wiley, ISBN 978-0-471-62334-2

[4] Research Summaries, Young Adolescent Development-Browse by Topic, Middle Ground

[5] Huang Tieying, You can't learn from Haidilao, Zhongxin Press, 2011.3.

[6] Wu Jing and $\mathrm{Lu}$ Xiaolan, Determining the Relationship between Chinese Employees' Ego-identity and Job Involvement, Human Rescource Development of China, 2016. 11p48-54

[7] Richard L. Hughes, Robert C. Ginnett\&Gordon J. Curphy, Leadership: Enhancing The Lessons of Experience, China Machine Press, 2016, 3. p472 